\title{
Selection of ornamental Glandularia hybrids potentially used as pot or bedding plants
}

\author{
L. Imhof ${ }^{1}$, M.A. Suárez ${ }^{1}$, E.C. Hick ${ }^{1}$, N. Cáceres ${ }^{1}$, E.E. Matoff ${ }^{2}$ and L. Galetto ${ }^{3}$ \\ ${ }^{1}$ Universidad Católica de Córdoba, Unidad Ejecutora UCC-CONICET (IRNASUS), Argentina \\ ${ }^{2}$ INTA, Agencia Regional Córdoba, Gobernador Roca esquina, La Coruña, Argentina \\ ${ }^{3}$ Departamento de Diversidad Biológica y Ecología, Facultad de Ciencias Exactas, Físicas y Naturales, Universidad Nacional \\ de Córdoba and Instituto Multidisciplinario de Biología Vegetal (CONICET-UNC), Argentina
}

\section{Summary}

As part of the breeding program of Glandularia (Verbenaceae), here we performed interspecific crosses to select the most outstanding materials and define trait associations for descriptors related to ornamental performance. The experimental material consisted of populations of three species of Glandularia and their offspring. Crosses were obtained by artificial hybridization using the diallel method. Reproductive efficiency values ranged from $10.4 \%$ to $60.7 \%$. Ornamental characterization on pot and bedding plants were obtained from hybrids and their parents, after analysation through a principal components analysis. The pot plant fitness index values for parents and offspring ranged between 0.56-0.76 and 0.56-0.78, respectively; the bedding index values for parents and offspring ranged between 0.17-0.99 and $0.15-0.99$, respectively. The features selected for the construction of the indices were effective for discriminating the ornamental aptitude of the different plant materials. Glandularia hybrids showed a remarkable ornamental performance for different purposes, some hybrids performing better as pot plants, others for bedding plants, and some for both.

\section{Keywords}

ornamental characterization, Glandularia spp., hybridization, indices, performance, reproductive efficiency

\section{Introduction}

Phenotypic diversity of ornamental plants may be increased using hybrids obtained between wild types of native plants that can then be introduced in the market (Stummel and Bosland, 2006). Ornamental plants are grown for decorative purposes in pots, hanging, and garden landscapes for pleasure or to enhance the environment (Muakrong et al., 2014). Characters such as flower color, corolla shape or persistence are selected because they are crucial for increasing the commercial value of ornamental plants. Breeding programs can be developed via the selection of parents from native populations as well as via hybridization of different species (Santos et al., 2014). Interspecific hybridization increases the possibility of genetic variation and improvement of ornamentals (Eeckhaut et al., 2006), being the basis of most of current crops of Rosa (Mercure et al., 2008); Chrysanthemum (Sun et al., 2010); Lilium (Zhang et al., 2012), among others. Hybridization is a positive contribution when

\section{Significance of this study}

What is already known on this subject?

- It is known that species of Glandularia are selfincompatible which favors cross fertilization.

What are the new findings?

- The generation of hybrids among native species of the genus Glandularia, as well as the evaluation of its pot and bedding performance, which would allow introduction to the ornamental market.

What is the expected impact on horticulture?

- The proposed characters could be adopted to evaluate the ornamental potential of other native or not-native species, for pot or bedding uses in a simple and efficient way.

the offspring has a higher performance than one or both parents, and some traits of interest are enhanced; for example, there are two levels of ploidy (tetraploids and diploids) within Rosa that can be used to develop disease-resistant varieties (Whitaker et al., 2010). Once a new offspring is generated, the following steps in the breeding program should be focused on characterizing and evaluating the offspring for selection. This methodology allows for a clear and simple comparison among hybrids. To facilitate the analysis of data obtained from characterization of parents and hybrids, Chamas and Matthes (2000) proposed an index to determine the potential of native ornamentals. They developed a systematic method and criteria for defining the ornamental potential of native species and proposed a composite index to evaluate the ornamental potential of tropical species (Heiden et al., 2006). The inclusion of different traits of the plant materials to calculate the index depends on the breeding objectives (Stumpf et al., 2007). Interspecific crosses have been documented for Glandularia since 1870. Schnack and Covas (1945) and Solbrig et al. (1968) conducted an extensive hybridization program for South American species. The success of an improvement program depends mainly on the choice of the germplasm. A successful choice provides populations of different species with the potential to develop traits of commercial interest and efficiency for the breeding program (Santos et al., 2011). In central Argentina, there are native populations of Glandularia glandulifera (Moldenke) Ragonese, G. peruviana L. Small and G. platensis (Spreng) Schnack and Covas. These species provide an interesting floriculture option to be used in semi-arid climatic conditions 
and to develop a breeding program for turning an undomesticated species into an economically viable hybrid for pot production and garden landscapes (Imhof, 2013). However, to the best of our knowledge, there is no history of experimental hybridization involving these species. Although these target species of Glandularia are essentially allogamous, it is possible to obtain plants through artificial interspecific hybridization and explore the ornamental performance of the hybrids compared to parents (Imhof et al., 2010). With the general purpose of developing a breeding program with Glandularia and then selecting hybrids for specific ornamental purposes, the goals of this study were (i) to perform Glandularia interspecific crosses in order to select some offspring with ornamental traits of interest; (ii) to define descriptors through different traits associations; and (iii) to evaluate the ornamental performance of these hybrids via a multivariate analysis.

\section{Materials and methods}

The temperatures during the evaluation period ranged from $0^{\circ} \mathrm{C}$ in the winter to $40^{\circ} \mathrm{C}$ in the summer for outdoor bed conditions, and not declined from $0^{\circ} \mathrm{C}$ (wireless sensor measured data) within the greenhouse. Annual rainfall for the study period was of $960 \mathrm{~mm}$. Greenhouse irrigation was through spray (1000 mm per year). No fertilizers have been added.

\section{Parents}

The material (populations of Glandularia species: Glandularia glandulifera (Moldenke) Ragonese, G. peruviana L. Small and G. platensis (Spreng) Schnack and Covas) to be used in the breeding program was collected from Córdoba province, Argentina. Parental plants were acclimated to culture conditions at the Catholic University of Cordoba $\left(31.66^{\circ} \mathrm{S}, 64.43^{\circ} \mathrm{W}\right)$.

\section{Hybrids}

The interspecific crosses between species were performed using the partial diallel method (Griffin, 1956); senescent and open flowers of the inflorescence were previously removed. Crosses were performed on recently open buds during anthesis. Flowers corresponding to the female parent were emasculated and fresh pollen grains from a parental male were deposited on stigmas via hand pollinations. Artificial outcrosses were done manually pollinating (hand-pollinated crosses) recently open flowers from each inflorescence. In the result section, the number of pollinated flowers of an inflorescence (maternal genotype) with the same pollen donor (paternal genotype) is indicated for each case. Then insufficient transfer of compatible pollen is expected to have the most pronounced effect on seed production and/or seed germination. Seeds resulting from different hand-crosses were collected, hydrated with gibberellic acid (100 ppm) and sown in pots inside germination modules. Data obtained were: fruit set (number of development fruits/number of pollinated flowers), seed set (number of seeds per fruit/number of ovules per ovary) and seed germination (\%). Reproductive efficiency (\%) was calculated as fruit set $\times$ seed set, following Dafni (1992). Only parents of hybrids evaluated for pot and bedding characterization are presented (not all the combinations). When the seedlings of the offspring had the first two true leaves, they were transplanted to pots containing a substrate composed of soil, compost and sand (1:1:1; v:v:v). The plants were grown in pots under greenhouse conditions. Each parent and the hybrids were multiplied asexually (lateral stem cuttings) to obtain 10 and 9 clones for pot and bedding characterization respectively. For pot plant characterization, clones were propagated by cuttings and cultivated in a mixture of peat and perlite $(3: 1 ; \mathrm{v}: \mathrm{v})$. Rooted cuttings were transplanted to plastic pots volume $(12.5 \mathrm{~cm}$ diameter $)$ on substrate consisting of soil, compost and perlite (1:1:1). The following characters of interest were measured: cover pot (CP; as percentage of surface covered by the plant in a pot), number of branches (NB), number of inflorescences (NI), inflorescence size (Is, measures width of the inflorescence), and color ( $\mathrm{C}$, color persistence over time). Cover pot (CP) was calculated by photographing each pot at an operator-pot distance of $80 \mathrm{~cm}$; photos were then processed with Image tool (version 2010), which provided the final CP value of each plant. Color was measured with a colorimeter (Minolta). Data of measurements were of 60 days after planting for cover pot (CP) and number of branches (NB) and full bloom for number of inflorescence (NI), inflorescence size (Is) and color (C). Friedman Test was used to compare pot variables between hybrids and their parents, because parametric assumptions were not met. In the Friedman Test the means corresponded to the ranks. Color variable was not statistically compared. Color changes through flower anthesis were included in the index (OPFI) assigning relative values to them because its ornamental importance.

Then, with the variables mentioned above, ornamental pot plant fitness index (OPFI) was calculated as follows: $\mathrm{OPFI}=(\mathrm{CP} \times 0.2)+(\mathrm{NB} \times 0.2)+(\mathrm{NI} \times 0.2)+(\mathrm{Is} \times 0.2)+(\mathrm{C} \times$ $0.2)$. The categories and relative weight value for the OPFI (ornamental pot fitness index) on each character were: 0.5

TABLE 1. Index values for the parents evaluated after hybridization through controlled hand pollinations.

\begin{tabular}{lccccc}
\hline Parent clones & Abbreviations & Species & OPFI & OBFI & OPFI+OBFI/2 \\
\hline UCCAA09112005 & AA & G. glandulifera & 0.76 & 0.66 & 0.71 \\
UCCAB09112005 & AB & G. glandulifera & 0.56 & 0.83 & 0.69 \\
UCCAD09112005 & AD & G. glandulifera & 0.66 & 0.83 & 0.75 \\
UCCAF09112005 & AF & G. glandulifera & 0.68 & 0.99 & 0.84 \\
UCCBB07122005 & BB & G. peruviana & 0.56 & 0.17 & 0.37 \\
UCCBE16112005 & BE & G. peruviana & 0.76 & 0.17 & 0.47 \\
UCCBM13122006 & BM & G. peruviana & 0.66 & 0.66 & 0.66 \\
UCCB013122006 & BO & G. peruviana & 0.76 & 0.66 & 0.71 \\
UCCCA23112005 & CA & G. platensis & 0.56 & 0.66 & 0.61 \\
UCCCF23112005 & CF & G. platensis & 0.56 & 0.33 & 0.45 \\
\hline
\end{tabular}

Abbreviations: OPFI: ornamental pot fitness index; OBFI: index of bedding ornamental fitness; OPFI+OBFI/2: combination of both indices. 
and 1 for the range $60-70 \%$; $71-80 \%$; more than $81 \%$ on cover pot (CP) respectively; 0.5 and 1 for the range less than 10; between 11 to 19 and more than 20 on number of branches (NB) and number of inflorescence (NI); less than 2; between 2 and 3 and more than $3(\mathrm{~cm})$ on inflorescence size (Is) and 0.8 for slight color change with time and 0.4 for strong color change with time. Replicated plants from different populations were penalized by assigning lower index values when plants presented the following characteristics: minor pot cover, low number of branches, low number or small diameter of inflorescence, or changes in corolla color as flower ages.

For bedding plant characterization, clones were propagated by cuttings and cultivated to full bloom, using the same procedure as that used for pot plants, but outside the greenhouse. Nine plants were placed per plot at $30 \mathrm{~cm}$ intervals. The following characters were measured: percentage of area covered by the plant in a bedding (Ca; \%), number of branches $(\mathrm{Nb})$ and number of inflorescences (Ni). Friedman Test was used to compare bedding variables between hybrids and their parents, because parametric assumptions were not met. In the Friedman Test the means corresponded to the ranks.

With the variables mentioned above ornamental bedding fitness index (OBFI) was calculated as follows: OBFI $=(\mathrm{Ca} \times$ $0.33)+(\mathrm{Nb} \times 0.33)+(\mathrm{Ni} \times 0.33)$. Data of measurements were of 360,375 and 420 days after planting for all characters. The categories and relative weight value for the OBFI (ornamental bedding fitness index) on each character were: $0,0.5$ and 1 for the range $60-70 \%$; $71-80 \%$; more than $81 \%$ on coverage area ( $\mathrm{Ca}$ ) respectively; $0,0.5$ and 1 for the range less than 50; between 50 to 90 and more than 90 on number of branches (NB) and 0, 0.4, 0.8 and 1 for the range less than 50; between 50 to 90 ; 90 to 130 and more than 131 on number of inflorescence (NI). Propagated plants of different populations were penalized by applying lower index values when plants presented one of the following characteristics: minor cover, low number of branches or low number of inflorescences. Measurements were taken on three dates: at 360,390 and 420 days after planting. The measurements for both parents and their respective hybrid were obtained when the plants have expressed the characters measured at their maximum expression in a pot (which coincides with the commercialization's plant-stage). Bed measurements were performed after a year from planting, evaluating the ornamental performance after plants surpass unfavorable conditions in different seasons (e.g., intense cold during winter and excessive heat during summer).

Data obtained in the indices were analyzed using a principal component analysis (PCA), which reduces the dimensionality of a data set consisting of a large number of variables, retaining the variation present in the data set as much as possible (Zou et al., 2006). Analyses were run using Infostat (Di Rienzo et al., 2011).

\section{Results}

\section{Parents}

Values of indices for parents are presented in Table 1. The clones (AA), (BE) and (BO) showed a better performance for pot planting, whereas (AB), (AD) and (AF) performed better for bedding than for pot plants. Three clones of G. glandulifera (Moldenke) Ragonese ((AA), (AD), (AF)) and one of $G$. peruviana L. Small (BO) showed the highest values $(>0.7)$ of the combined indices.

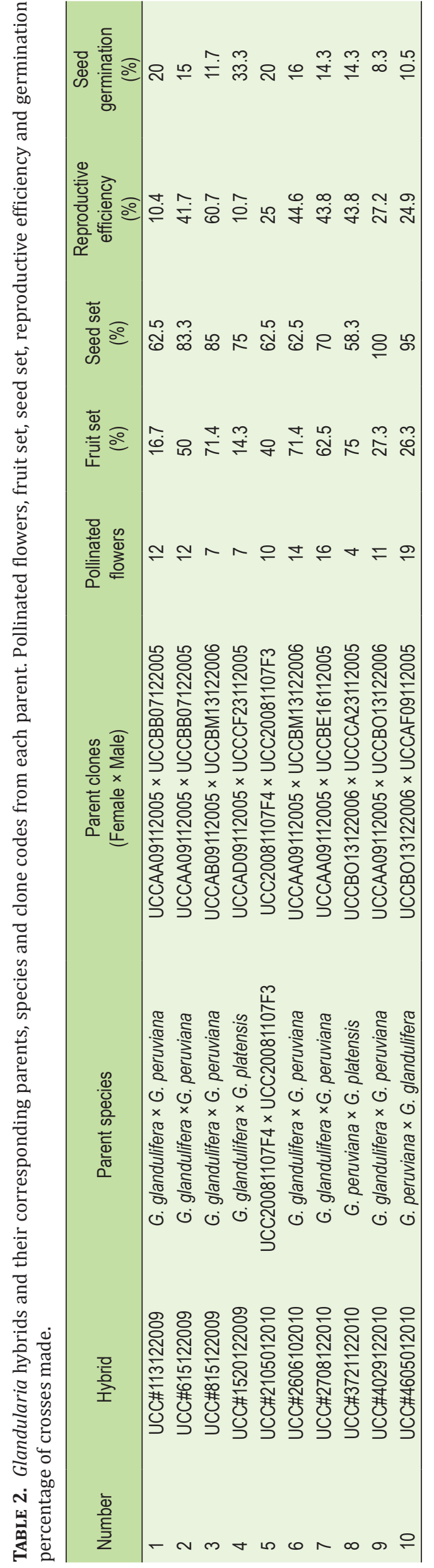


TABLE 3. Statistical results (non-parametric Friedman Test) comparing each hybrid with their parents (using the mean ranks for pot and bedding variables used in the indices).

\begin{tabular}{|c|c|c|c|c|c|}
\hline \multirow{3}{*}{ Hybrid number } & \multicolumn{3}{|c|}{ Mean ranks for bedding variables $(n=27)$} & \multirow{2}{*}{\multicolumn{2}{|c|}{ Friedman Test }} \\
\hline & \multirow{2}{*}{ Hybrid } & \multicolumn{2}{|c|}{ Parents } & & \\
\hline & & Female & Male & $T$ & $p$ \\
\hline 1 & $1.96 \mathrm{a}$ & $2.26 \mathrm{a}$ & $1.78 \mathrm{a}$ & 1.66 & 0.199 \\
\hline 2 & $2.76 \mathrm{c}$ & $1.83 b$ & $1.41 \mathrm{a}$ & 21.41 & $<0.0001$ \\
\hline 3 & $3 b$ & $1.57 \mathrm{ab}$ & $1.43 \mathrm{a}$ & 121.87 & $<0.001$ \\
\hline 4 & $2.81 \mathrm{C}$ & $1.98 b$ & $1.2 \mathrm{a}$ & 49.42 & $<0.0001$ \\
\hline 5 & $2.78 b$ & $1.65 a b$ & $1.57 \mathrm{a}$ & 26.7 & $<0.0001$ \\
\hline 6 & $2.83 \mathrm{c}$ & $1.69 a b$ & $1.48 \mathrm{a}$ & 30.67 & $<0.0001$ \\
\hline 7 & $2.81 \mathrm{C}$ & $1.94 b$ & $1.25 \mathrm{a}$ & 43.81 & $<0.0001$ \\
\hline 8 & $2.91 \mathrm{C}$ & $1.76 \mathrm{~b}$ & $1.33 \mathrm{a}$ & 54.1 & $<0.0001$ \\
\hline 9 & $3 b$ & $1.48 \mathrm{a}$ & $1.52 \mathrm{a}$ & 84.4 & $<0.0001$ \\
\hline 10 & $2.89 \mathrm{c}$ & $1.26 \mathrm{a}$ & $1.85 b$ & 62.6 & $<0.0001$ \\
\hline \multirow{3}{*}{ Hybrid number } & \multicolumn{3}{|c|}{ Mean ranks for pot variables $(n=10)$} & \multirow{2}{*}{\multicolumn{2}{|c|}{ Friedman Test }} \\
\hline & \multirow{2}{*}{ Hybrid } & \multicolumn{2}{|c|}{ Parents } & & \\
\hline & & Female & Male & $\mathrm{T}$ & $p$ \\
\hline 1 & $2.4 \mathrm{~b}$ & $2.1 \mathrm{~b}$ & $1.5 \mathrm{a}$ & 10.88 & 0.0001 \\
\hline 2 & $2.26 \mathrm{~b}$ & $2.18 b$ & $1.56 \mathrm{a}$ & 7 & 0.0016 \\
\hline 3 & $2.51 \mathrm{~b}$ & $1.65 \mathrm{a}$ & $1.84 \mathrm{ab}$ & 11.26 & 0.0001 \\
\hline 4 & $2.31 \mathrm{~b}$ & $2.16 b$ & $1.53 \mathrm{a}$ & 8.8 & 0.0004 \\
\hline 5 & $2.88 b$ & $1.54 \mathrm{a}$ & $1.59 \mathrm{ab}$ & 73.17 & $<0.0001$ \\
\hline 6 & $2.53 c$ & $2.05 b$ & $1.43 a$ & 18.04 & $<0.0001$ \\
\hline 7 & $1.89 a$ & $2 a$ & $2.11 \mathrm{a}$ & 0.55 & 0.58 \\
\hline 8 & $2.1 \mathrm{~b}$ & $2.29 \mathrm{~b}$ & $1.61 \mathrm{a}$ & 5.5 & 0.0056 \\
\hline 9 & $2.49 \mathrm{c}$ & $1.39 \mathrm{a}$ & $2.13 b$ & 20.06 & $<0.0001$ \\
\hline 10 & $2.21 \mathrm{~b}$ & $2.26 \mathrm{~b}$ & $1.53 \mathrm{a}$ & 8.42 & 0.0005 \\
\hline
\end{tabular}

Means with common letter are not significantly different.

\section{Hybrids}

The hybrid code, parent species and clone number used for the hybridization program are presented in Table 2, which shows pollinated flowers, fruit set, seed set, reproductive efficiency and germination percentage. Reproductive barriers prevent fusion of male and female gametes originating from individuals of different species and/or development of fertilized ovule into viable seed. Average fruit production (successful mating) obtained through hand-pollination ranged between $14.3 \%$ (hybrid 4) to $75 \%$ (hybrid 8 ). Reproductive efficiency (Dafni's formula) ranged between 10.4\% (hybrid 1) to $60.7 \%$ (hybrid 3). In the case of pot variables, hybrid 7 presented no significant differences with at least one of its parents. In all the other hybrids significant differences with their parents were observed and hybrid values were superior (Table 3). The exceptions were hybrids 8 and 10 with higher values compared to the male parents but lower compared to female parents. For bedding variables, all hybrids presented higher values compared to their parents for bedding plants (with significant differences), except hybrid 1 (media values for the hybrid variables were higher than male parent and lower than female parent, but the differences were not significant). These results showed, in general, that most hybrids displayed a superior performance on bedding conditions than their parents. Table 3 shows the results of Friedman Tests.

In Figure 1 PCA plot showed the performance of hybrids on pot (Figure 1a) and bedding conditions for each period of measurement (Figure 1b-d). On Figure 1a, PC1 and PC2 ex- plained $93.4 \%$ of the total variability. In this case, hybrids 2 , 3,9 and 10 were positively associated in coverage area (Ca) and hybrids 1, 4, 5 and 7 negatively associated with the index (OPFI). On Figures 1b-d, PC1 and PC2 explained 85.3\%, $98.6 \%$ and $95 \%$ of the total variability. These plots allowed to show the evolution of the performance of the hybrids under bedding conditions as the plant grew.

Hybrid 9 was positively associated with bedding index (OBFI) on the first measurement (Figure 1b) and then it can maintain this performance (Figure 1c and d); in the second measurement hybrids 6, 8 and 10 had similar high performances as hybrid 9 (Figure 1c). Finally, in the last measurement the hybrids $3,5,6,9$ and 10 were positively associated with the index variable, showing that hybrids 3 and 5 improved their performance, while hybrid 8 could not maintain its bedding performance (Figure $1 \mathrm{~d}$ ).

\section{Discussion}

Reproductive efficiency of the hybrids showed low to medium values (10.4 to $60.7 \%$ ). Indicators such as plant reproductive success and total number of fruits produced by plants are usually correlated with the reproductive system (Popoola et al., 2011; Barret, 2013); however, the causes for a low reproductive efficiency are complex. Reproductive success depends on numerous factors controlling the process of flowering, fruiting and fruit production (Kudo, 2006). Some of them may be population size, floral display, plant size, phenological characters (Silva et al., 2010), the intervention of pollinators and genetic load (Morales and Galetto, 2003). 

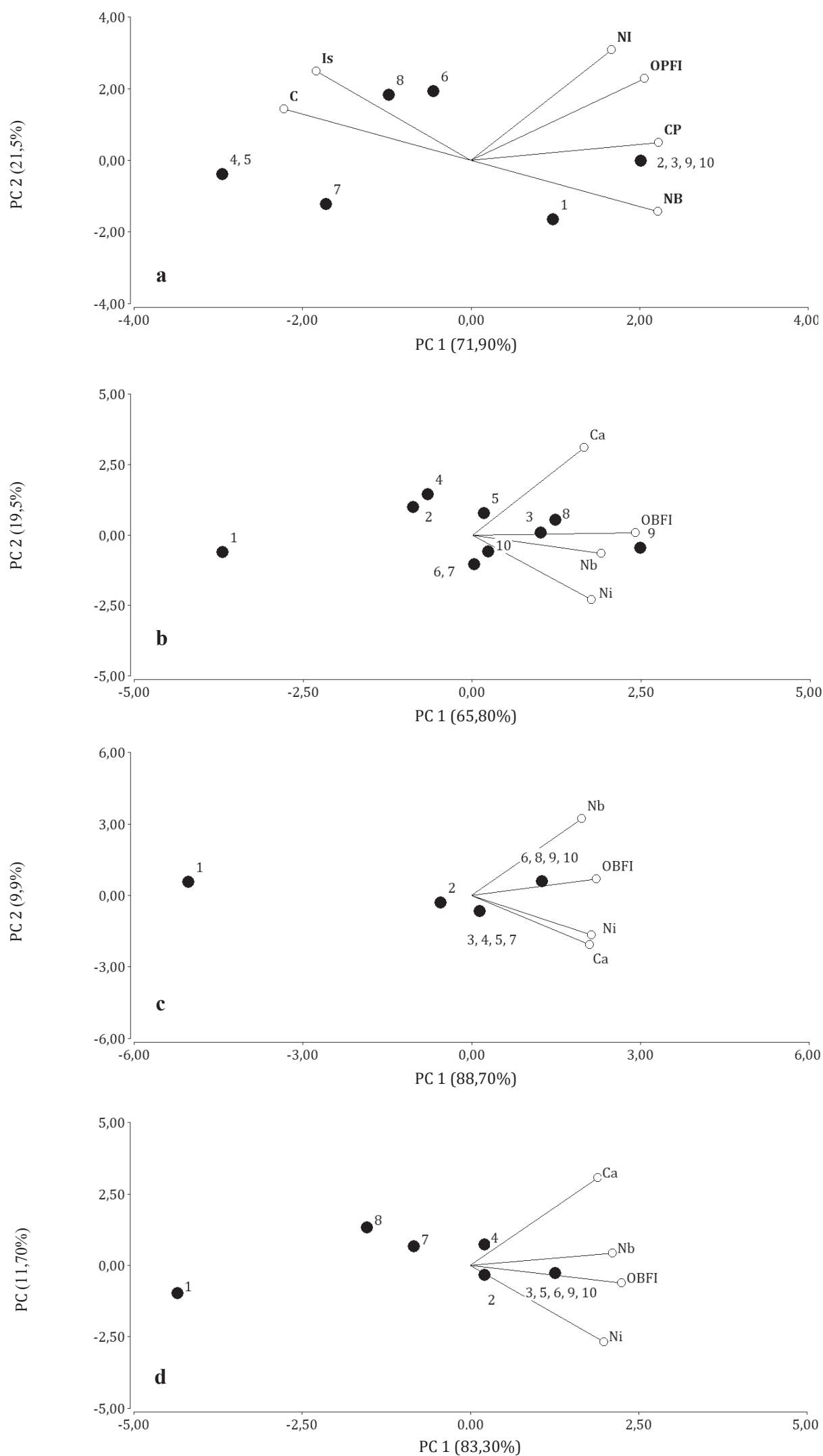

FigURE 1. Plot of principal component indices of Glandularia hybrids; a) Ornamental Pot Plant Fitness Index: OPFI, NB: number of branches; NI: number of inflorescences; Is: size of inflorescence; C: color; OPFI: ornamental pot plant fitness index; b) OBFI: bedding ornamental fitness index on the first measurement date with Ca: percentage of area covered; Nb: number of branches; Ni: number of inflorescence; c) OBFI: index of bedding ornamental fitness on the second measurement; with Ca: percentage of area covered; $\mathrm{Nb}$ : number of branches; Ni: number of inflorescence; d) OBFI: index of bedding ornamental fitness on the third measurement; with Ca: percentage of area covered; Nb: number of branches; Ni: number of inflorescence. 
Genetic load in self-incompatible species has been suggested as the cause of low fertility due to the high incidence of developmental abnormalities, lethal effects in the zygote and embryo death, rarely appearing in self-compatible species (Morales and Galetto, 2003). The analyzed Glandularia species are self-incompatible, i.e., pollen tubes are rejects at the ovarian level (Imhof et al., 2010). These traits can explain to difficulties to obtain successful hybrids. Once the hybrid is achieved, morphological characterization is an essential step in breeding programs because it allows us to monitor genetic quality (Radmann and Oliveira, 2003). The methodology used by Chamas and Matthes (2000) for evaluating ornamental potential of a plant species provides an index to characterize the hybrids and their parents. The features selected to construct OPFI (pot cover, number of branches, number of inflorescences, inflorescence size, color) and OBFI (bedding cover, number of inflorescences, number of branches) were effective in discriminating the ornamental potential of hybrids and identifying the most promising ones for each character. Hybrids number 3, 6, 8, 9 and 10 presented the highest values for a combined index (OPFI + OBFI). All these hybrids showed excellent performance in bedding conditions, and hybrids 6 and 3 , also in pot cover, number and size of inflorescences. Nevertheless, hybrid 3 showed changes in the color of the flowers over time, which is not desirable for commercial purposes. Hybrids 9 and 10 exhibited excellent pot plant cover, and high values in number of branches and number of inflorescences, as hybrid 8; however, the latter showed intermediate performance for pot cover. The characters chosen for the construction of the indices were efficient to discriminate the ornamental performance for pot and bedding of the hybrid collection. To our knowledge, ornamental fitness indices in Glandularia are presented here for the first time. Ornamental breeding is a continuous process for the formation of hybrids and varieties. The increased pot and bedding performance of the hybrids compared to the average index values of their parent ranged between 15.1 and 36\%. In general, it was observed for the most promising hybrids that the female parental belonged to the species G. glandulifera (but see one of the accessions belonged to a female-parental of G. peruviana), while pollen donors (male parental) belonged to the three Glandularia species. Although the chosen parents showed good ornamental pot and bedding performances, the first generation of hybrids showed higher values than their parents in most cases. Of the promising hybrids, the materials 9, 3 and 8 were not close to any particular parent, but to both equally; in the case of hybrid 10, it was similar to male parent and 6 to the female parent. In these last two cases, hybrid 10 was grouped with its male parental in CP (cover pot), NB (number of branches) for pot characters; and Is (size of inflorescence), Ca (percentage of area covered) and $\mathrm{Nb}$ (number of branches) for bedding characters; while hybrid 6 was grouped with its female parental in CP and NB for pot characters and Ca for bedding. In most cases, it was observed in the promising materials (hybrids 9, 10, 3, 6 and 8 ) have exceeded in their number of inflorescence and percentage of area covered for bedding from their female parent and proved to be superior in number of inflorescence and coverage area on pot and bedding situation from their male parent.

At the same time, hybrids that showed an excellent performance under pots conditions, conserved their performance on bedding conditions. Those materials with a medium to regular pot performance improved their bedding performance in some cases. If a hybrid presented a good response in pots conditions, it would be expected the same behavior under bedding conditions; in the cases that the pot performance was good but not for bedding, a low performance was observed at the beginning of the spring (first measurement). These results are very promising because they validate interspecific hybridization as a useful tool for the Glandularia breeding program and allow us to explore in the future the hybrid vigor in the selected plant material. Moreover, the acquirement of Glandularia hybrids with excellent performance in pot and bedding conditions, such as materials 3 , 9 and 10, is very auspicious for the improvement of the ornamental program. Ornamental plants are grown for decoration, pleasure purposes, or to improve the environment. The aesthetic aspect of many ornamental plants refers to beauty and harmony (Hooper et al., 2008). Moreover, the demand for ornamental plants is a consequence of the country's economic growth and quality of life (Muakrong et al., 2014). The Glandularia hybrids with potential for ornamental use are expected not only to have good pot and bedding performance but also adequate aesthetic parameters, taking into account specific characteristics of native ornamental plants that are appreciated by different social actors. Moreover, these hybrids of Glandularia collection present the necessary variation in aesthetic traits, compared with the original parental populations, to be suitable for a promising ornamental market within the semiarid region of central Argentina.

\section{Acknowledgments}

We thank two anonymous reviewers for useful comments and suggestions that considerably improved previous versions. For financial support research team of the UCC thanks IRNASUS (UCC-CONICET), Mincyt Córdoba and INTA; and Leonardo Galetto thanks SECyT (UNC), CONICET and FONCyT.

\section{References}

Barrett, S.C. (2013). The evolution of plant reproductive systems: how often are transitions irreversible? P. Roy. Soc. Lond. B. Bio. 280(1765), 913. https://doi.org/10.1098/rspb.2013.0913.

Chamas, C.C., and Matthes, L.A.F. (2000). Método para levantamento de espécies nativas com potencial ornamental. Ornam. Hortic. 6(1), 53-63. doi: 10.14295/rbho.v6il.63.

Dafni, A. (1992). Pollination Ecology, a Practical Approach (New York: Oxford University Press), 250 pp.

Di Rienzo, J., Casanoves, F., Balzarini, M., Gonzalez, L., Tablada, M., and Robledo, Y.C. (2011). Infostat versión 2011. Grupo Infostat, FCA, Universidad Nacional de Córdoba, Argentina. URL http://www. infostat.com.ar 8, 195-199.

Eeckhaut, T., Van Laere, K., De Riek, J., and Van Huylenbroeck, J. (2006). Overcoming interspecific barriers in ornamental plant breeding. In Floriculture, Ornamental and Plant Biotechnology: Advances and Topical Issues (London: Global Science Books), p. 540-551.

Griffin, B. (1956). Concept of general and specific combining ability in relation to diallel crossing systems. Aust. J. Biol. Sci. 9(4), 463-493. https://doi.org/10.1071/BI9560463.

Heiden, G., Baribieri, R., and Stumpf, E. (2006). Consideracoes sobre o uso de plantas ornamentais nativas. Ornam. Hortic. 12(1), 2-7. https://doi.org/10.14295/rbho.v12i1.60.

Hooper, V.H., Endter-Wada, J., and Johnson, C.W. (2008). Theory and Practice Related to Native Plants, a Case Study of Utah Landscape Professionals. Landscape J. 27(1), 127-141. https://doi. org/10.3368/lj.27.1.127. 
Imhof, L., Borja, M., and Facciuto, G. (2010). Breeding system of Glandularia species native to Argentina. Acta Hortic. 855, 149-152. https://doi.org/10.17660/ActaHortic.2010.855.20.

Imhof, L. (2013). Bases for improvement in Glandularia for ornamental purposes. Doctoral Thesis (Córdoba: Catholic University of Córdoba) (\#000182064) http://200.45.112.19/F/YCMY2FRIUPN13VB83VN78644DHFFPHTX3N7SSPDSI7JH8EG6N101946?func=itemglobalexp\&doc_number $=000182064 \&$ item_sequence $=000010 \&$ sub_library=UCCC.

Kudo, G. (2006). Flowering phenologies of animal-pollinated plants: reproductive strategies and agents of selection. In Ecology and Evolution of Flowers, L. Harder, and S. Barrett, eds. (Oxford: Oxford University Press), p. 139-158.

Mercure, M., and Bruneau, A. (2008). Hybridization between the escaped Rosa rugosa (Rosaceae) and native $R$. blanda in eastern North America. Am. J. Bot. 95(5), 597-607. https://doi.org/10.3732/ ajb.2007385.

Morales, C.L., and Galetto, L. (2003). Influence of compatibility system and life form on plant reproductive success. Plant Biol. 5(5), 567-573. https://doi.org/10.1055/s-2003-44794.

Muakrong, N., Chamman, P., Patcharin, T., and Peerasak, S. (2014). Breeding field crops for ornamental purpose: a case in Jatropha spp. Agrivita 36(3), 229-234. https://doi.org/10.17503/ Agrivita-2014-36-3-229-234.

Popoola, J.O., Adegbite, A.E., and Obembe, O.O. (2011). Reproductive mechanisms and pollen characterization in some accessions of an underutilized legume: (Sphenostylis stenocarpa Hochst Ex. A. Rich) harms. Int. J. Biodivers. Conserv. 3(6), 185-192.

Radmann, E., and Oliveira, R. (2003). Caracterizacao de cultivares apirenicas de citros de mesa por meio de descritores morfológicos. Pesq. Agropec. Bras. 38(9), 1123-1129. https://doi.org/10.1590/ S0100-204X2003000900015.

Santos, E., Souza, M., Viana, A., Almeida, A., Freitas, J., and Lawinscky, P. (2011). Multivariate analysis of morphological characteristics of two species of passion flower with ornamental potential and hybrids between them. Genet. Mol. Res. 10(4), 2457-2471. https://doi. org/10.4238/2011.0ctober.13.3.

Santos, R., Do Rego, E., Borem, A., Nascimento, M., Nascimento, N.F.F., Finger, F., and Rego, M.M. (2014). Epistasis and inheritance of plant habit and fruit quality traits in ornamental pepper (Capsicum annuum L.). Genet. Mol. Res. 13(4), 8876-8887. https://doi. org/10.4238/2014.0ctober.31.3.

Schnack, B., and Covas, G. (1945). Hibridación interespecífica en Glandularia (Verbenáceas). Darwiniana 7(1), 71-79. http://www. jstor.org/stable/23211595.

Silva, C.A., Vieira, M.F., and Amaral, C.H.D. (2010). Floral attributes, ornithophily and reproductive success of Palicourea longepedunculata (Rubiaceae), a distylous shrub in southeastern Brazil. Braz. J. Bot. 33(2), 207-213. https://doi.org/10.1590/S010084042010000200002 .

Solbrig, O.T., Passani, C., and Glass, R. (1968). Artificial hybridization between different polyploid levels in Glandularia (Verbenaceae). Am. J. Bot. 55(10), 1235-1239. https://doi. org/10.1002/j.1537-2197.1968.tb07490.x.

Stummel, J., and Bosland, P. (2006). Ornamental pepper, Capsicum annuum. In Flower Breeding and Genetics: Issues, Challenges and Opportunities for the $21^{\text {st }}$ Century, N. Anderson, ed. (The Netherlands: Springer), p. 561-599. https://doi.org/10.1007/9781-4020-4428-1.

Stumpf, E.R.T., Heiden, G., Barbieri, R.L., Fisher, S.Z., Neitzke, R.S., Zanchet, B., and Grolli, P.R. (2007). Metodo para avaliacao da potentialidade ornamental de flores e folhagens de corte nativas e nao convencionais. Ornam. Hortic. 13(2), 123-133.
Sun, C.Q., Chen, F.D., Teng, N.J., Liu, Z.L., Fang, W.M., and Hou, X.L. (2010). Interspecific hybrids between Chrysanthemum grandiflorum (Ramat.) Kitamura and C. indicum (L.) Des Moul. and their drought tolerance evaluation. Euphytica 174(1), 51-60. https://doi. org/10.1007/s10681-009-0117-z

Whitaker, V.M., Bradeen, J.M., Debener, T., Biber, A., and Hokanson, S.C. (2010). Rdr3, a novel locus conferring black spot disease resistance in tetraploid rose: genetic analysis, LRR profiling, and SCAR marker development. Theor. App. Genet. 120(3), 573-585. https://doi. org/10.1007/s00122-009-1177-0.

Zhang, X., Ren, G., Li, K., Zhou, G., and Zhou, S. (2012). Genomic variation of new cultivars selected from distant hybridization in Lilium. Pl. Breeding 131(1), 227-230. https://doi.org/10.1111/ j.1439-0523.2011.01906.x

Zou, H., Hastie, T., and Tibshirani, R. (2006). Sparse principal component analysis. J. Comput. Graph. Stat. 15(2), 265-286. https:// doi.org/10.1198/106186006X113430.

Received: Jun. 2, 2017

Accepted: Nov. 28, 2017

Addresses of authors:

Lelia Imhof ${ }^{1, *}$, Mario A. Suárez ${ }^{1}$, Emmanuel C. Hick ${ }^{1}$, Natalia Cáceres ${ }^{1}$, Evangelina E. Matoff ${ }^{2}$, and Leonardo Galetto ${ }^{3}$

${ }^{1}$ Universidad Católica de Córdoba-Unidad Ejecutora UCCCONICET (IRNASUS), Av. Armada Argentina 3555, Argentina

${ }^{2}$ INTA-Agencia Regional Córdoba, Gobernador Roca esquina La Coruña, Argentina

${ }^{3}$ Departamento de Diversidad Biológica y Ecología, Facultad de Ciencias Exactas, Físicas y Naturales, Universidad Nacional de Córdoba and Instituto Multidisciplinario de Biología Vegetal (CONICET-UNC), Argentina *Corresponding author; leliaimhof@gmail.com 